and no doubt cones had been erected before the time of Cheops, and had their meaning and uses. Probably they were first made of earth, and the circular base would no doubt be set out by a cord, as above described. Cheops, by his architect, squared the circular base; getting thereby lines much better adapted to stone work, whilst still keeping the old sacred emblem, though in a developed form. It may, I believe, be traced down to many modern forms not often suspected of bearing any relation to it.

Belper, January I'

J. G. JACKSON

\section{Acoustical Effects of Atmospheric Pressure}

ON tapping an ordinary bell-jar receiver after exhaustion, the following was noticed. The note derived from percussion after exhaustion was sensibly of a higher grade than that obtained from the glass containing air. On gradually letting the air in, the note sank directly as the amount of air so introduced. We conclude that the phenomena here recorded are connected with the atmospheric pressure, and that the note yielded is a function of the atmospheric fressure. Can any of your readers suggest a method for the investigation of the observed facts, if no investigations have been before made on the subject.

Rugby, January 19

G. RAYLEIGH VICARS

\section{TRANSATLANTIC LONGITUDES}

$\mathrm{T} \mathrm{T}$ will be remembered that a preliminary account of the results of the transatlantic longitude determination of 1872 was published in Vol. xxii. of the Proceedings of the American Association for the Advancement of Science. We have now received the final report of Mr. Hilgard, which embodies not only the results, but also the observations, and which sets forth concisely the manner in which the former were deduced from the latter.

The importance of fixing with the greatest precision achievable, the longitude of some point in the cuast survey triangulation with reference to Greenwich, led the U.S. Government promptly to make use of the means afforded by the completion of the Atlantic telegraph cable from Ireland to Newfoundland.

The first telegraphic longitude determination through it, made under the direction of Dr. B. A. Gould, in 1866 , although it surpassed in exactness all results obtained by different methods was subject to a sniall but indeterminate correction, the "personal equation "between the Anerican and the standard Greenwich observer.

Use was therefore made of the French cable in 1870 to make another determination under different circunstances, and under the charge of $\mathrm{Mr}$. Dean the longitude difference between Brestand Cambridge, U.S., as before, was obtained; but as at that time no cable was in operation between Brest and England, the connecting link, Brest-Greenwich, remained undetermined until 1872 , when Mr. Hilgard took charge of the work necessary to supply this deficiency, and since the opportunity was afforded, to repeat the Transatlantic determination. This time an intermediate station, St. Pierre, on the American side, was introduced, thus varying still more the conditions under which this third determination was made.

The general plan of operations was to unite at Brest time signals from St. Pierre, Greenwich, and Paris. The co-operation at the last-named stations of the AstronomerRoyal, Sir. G. B. Airy, and of M. Delaunay, and the generosity of the telegraph companies, enabled Mr. Hilgard to finish the work successfully in September of that year.

We can only advert briefly to one or two points of interest. The accordance of the results appears to have been due in a great measure to the attention given to the accurate determination of the relative personal errors of the observers, which gave also indirectly the "personal equation" correction, lacking in the longitude determination of 1866 .

1 Final leeport on the 1)etermination of ${ }^{2} 872$, with a kertew of Presious

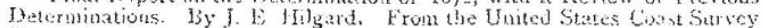
Report for 37 .
Incidentally, the "wave-time" of the cable signals was deduced, and on the assumption of equality in time in either direction, the resulting wave-time from Brest to St. Pierre, through a length of cable equal to 2,979 statute miles, is given as $05.35 \mathrm{I} \pm \mathrm{s}$. 003 .

The final results are given as follows, and the author remarks "that the close agreement of the three independent determinations made in different years is no less surprising than it is satisfactory." Even if we assume, as Mr. Hilgard evidently does, the identity of the results as accidental within the limits of the probable errors assigned, the determination must be characterised as being of the highest order of precision.

Longitude of Cambridge (Harvard Colleye Observatory' dome) west of Greenzusch (meridian) :-

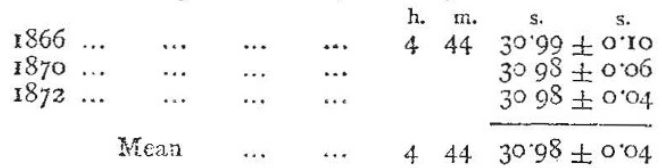

Referring this mean value to Paris (meridian of France) we have :-

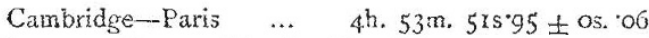

These results, combined with elaborate determinations of the longitude difference, Washington-Cambridge, give :-

$$
\begin{aligned}
& \text { Washington (Naval Observatory) } \\
& \text {-Greenwich } \\
& \text { Washington (Naval Observatory) } \\
& \text { - Parils } \\
& \text { h. } \mathrm{m}, \mathrm{s} . \\
& 5812.09 \pm 0.05 \\
& \begin{array}{lll}
517 & 3305 \pm 0.07
\end{array}
\end{aligned}
$$

We may, therefore, consider the geographical position of the Washington Observatory as one of the best determined in reference to others.

One of the incidental but highly important results of this expedition is the longitude difference Greenwich.Paris, the accuracy of which was checked by the conditions involved in the closing of the longitude triangle Greenwich-Paris-Brest. The result, om. 205.97 must now supersede the value obtained by Mr. Leverrier in 1854 , which it exceeds by nearly half a second.

\section{ANTOINE CESAR BECOUEREL}

$T$ is with regret that we record the deatin of the noted French physicist, Prof. Becquerel, which occurred on January 18, in Paris. Antoine César Becquerel was born at Châtillon-sur-Loing, in the Loiret department, March 8 , I738. After completing a course in the Paris Polytechnic, he entered, in I808, the Imperial Engineer Corps. It was no time of idleness for young officers, and he was shortly in active service, taking part in the entire Sparish campaign under General Luchet. Here he was present at the sieges of Torbosa, Tarragona, Lagonte, and Valencia, and manifested such marked abilities that in I8I2 he returned to Paris to receive the rank of captain, and be presented with the Cross of Chevalier of the Legion of Honour, from Napoleon's own hands. In the following year he was sent by the Emperor to complete the fortifications on the German frontier. At the fall of the empire, in 1815 , he resigned his position as chief of battalion in the Engineer Corps, and devoted himself exclusively to physical and chemical research, accepting a position as teacher in the Musée d'Histoire Naturelle, of Paris. In 1837 he was made professor in this institution and occupied this position up to the time of his death. Shortly after entering upon his scientific career he commenced the remarkable series of investigations in electricity and magnetism which have been uninterruptedly continued during the past half-century, and have linked his mame closely with every branch of these two leading deparments of physics. In themo-electricity Becquerel carried out a large number of experiments on the 